\title{
Processos de subjetivação juvenil nas escolas católicas
}

Eder D’Artagnan Ferreira Guimarães ${ }^{1}$

\begin{abstract}
Resumo:
Este artigo analisa a relação entre educação católica e constituição subjetiva dos adolescentes, a partir de dados coletados em uma pesquisa de doutoramento sobre o lugar das escolas católicas no cenário educacional contemporâneo. Foram utilizados questionários abertos com 157 estudantes secundaristas de 6 escolas católicas de Belo Horizonte (MG), abordando questões relacionadas à experiência escolar, participação em projetos e contribuições da escola à sua formação pessoal; os dados foram analisados a partir da Epistemologia Qualitativa e seu conceito de sentidos subjetivos. As percepções dos estudantes, considerados ao mesmo tempo em sua condição de adolescentes, possibilitam compreender a relação entre a educação católica e os processos de socialização, sociabilidade e subjetivação juvenil. Constata-se nestas escolas a diversidade inerente a qualquer espaço-tempo escolar, no que se refere a interpretações sobre a educação católica, ao final da escolarização básica; influência deste estilo educativo na constituição subjetiva dos estudantes; desenvolvimento do sentido de solidariedade; compreensão da cidadania e da participação social; e autopercepção a partir dos circuitos institucionais relacionados à escola.
\end{abstract}

\section{Palavras-chave:}

Ensino médio. Escola católica. Subjetivação juvenil. Estudantes adolescentes.

\section{Youth subjectivation processes in Catholic schools}

\begin{abstract}
This article analyses the relationship between Catholic education and the subjective constitution of adolescents, based on data collected in a doctoral research on the place of Catholic schools in the contemporary educational scenario. Open questionnaires were used with 157 high school students from 6 Catholic schools in Belo Horizonte (MG), addressing issues related to school experience, participation in projects and school contributions to their personal formation; the data were analysed using Qualitative Epistemology and its concept of subjective meanings. The students' perceptions, considered at the same time as teenagers, make possible to understand the relationship between Catholic education and the processes of socialization, sociability, and youth subjectivation. In these schools, there is a diversity inherent in any school space-time, regarding interpretations about Catholic education, at the end of basic schooling; influence of this educational style on the students' subjective constitution; development of the sense of solidarity; comprehension of citizenship and social participation; and self-perception from the institutional circuits related to the school.
\end{abstract}

Keywords: High school. Catholic school. Youth subjectivation. Teenagers students.

1 Doutorando em Educação pela Universidad Nacional de Rosário, Argentina. E-mail: ederdarta@gmail.com. ORCID iD: http:// orcid.org/0000-0002-9064-8059. 


\section{Procesos de subjetivación juvenil en las escuelas católicas}

Resumen: Este artículo analiza la relación entre la educación católica y la constitución subjetiva de los adolescentes, a partir de datos recogidos en una investigación doctoral acerca del lugar de la escuela católica en el escenario educativo contemporáneo. Se utilizaron cuestionarios abiertos con 157 estudiantes de secundaria de 6 escuelas católicas en Belo Horizonte (MG), abordando temas relacionados con la experiencia escolar, participación en proyectos y contribuciones de la escuela a su formación personal; los datos fueron analizados utilizando la Epistemología Cualitativa y su concepto de significados subjetivos. Las percepciones de los estudiantes, considerados al mismo tiempo como adolescentes, permiten comprender la relación entre la educación católica y los procesos de socialización, sociabilidad y subjetividad juvenil. En estas escuelas se advierte la diversidad inherente a cualquier escuela espacio-tiempo, en cuanto a las interpretaciones sobre la educación católica, al final de la escolarización básica; influencia de este estilo educativo en la constitución subjetiva de los estudiantes; desarrollo del sentido de solidaridad; comprensión de la ciudadanía y la participación social; y autopercepción desde los circuitos institucionales relacionados con la escuela.

Palabras clave: Bachillerato. Escuela Católica. Subjetivación juvenil. Adolescentes estudiantes.

\section{Introdução}

As culturas contemporâneas evidenciam a emergência de novas subjetividades e tramas sociais que desafiam os pesquisadores a desvendar os processos, contextos e experiências a partir dos quais os adolescentes e jovens se tornam sujeitos. Como são múltiplos os fatores que concorrem para as definições da identidade pessoal e social, a partir de experimentações em distintas esferas da vida (INSTITUTO CIDADANIA, 2004), demandam atenção tanto os referenciais teóricos sobre as juventudes quanto às especificidades dos ambientes familiares, sociais e institucionais por onde os jovens circulam e expressam sua condição juvenil.

As escolas católicas constituem um campo de investigação pouco explorado nos estudos sobre o fenômeno juvenil. Ainda que se encontrem pesquisas e reflexões acerca do ensino médio, especialmente na escola pública, são escassas as produções focadas nas escolas privadas confessionais e nos estudantes que aí se tornam adolescentes e jovens. Considerando-se que o conceito de juventude abrange a diversidade interna deste grupo social, os estudantes secundaristas das escolas católicas constituem um campo a desvendar. Vivendo as questões identitárias próprias desta etapa de vida, apresentam aspectos comuns a adolescentes e jovens de outras realidades, mas os aspectos sociais, culturais e religiosos aportam especificidades à constituição destes sujeitos jovens. Que há de específicos entre eles? Que sujeitos se constituem a partir do espaço-tempo escolar católico? Como percebem a influência da educação católica sobre sua constituição subjetiva?

Este artigo nasce da análise parcial de dados obtidos numa pesquisa de doutoramento do tipo qualitativo, tendo como tema O lugar das escolas católicas no cenário educacional contemporâneo, vinculada à Universidade Nacional de Rosario - UNR, na Argentina. Ainda que a pesquisa tenha envolvido também gestores, educadores e pastoralistas, aqui se faz um recorte específico das percepções dos estudantes secundaristas de seis colégios católicos de Belo Horizonte (MG), que atendem em geral estudantes de classe média alta e classe média ${ }^{1} .157$ deles, todos cursando os dois últimos anos do ensino médio, participaram da pesquisa, por livre adesão; para a coleta de dados, foi utilizado um questionário escrito, escolhido por "facilitar expressões do sujeito" e permitir a construção "dos sentidos subjetivos e dos processos simbólicos" que representam "a possibilidade

1 Todos os colégios pesquisados contam com estudantes bolsistas, mas aqui não se faz esta distinção. 
de posicionar o sujeito, de forma rápida e simples, diante de indutores que facilitem o trânsito para outros indutores diferentes" (GONZÁLEZ REY, 2005, p. 51). Os estudantes responderam a 10 questões abertas sobre sua trajetória escolar, incluindo temas como currículo, formação, dinâmica pedagógica, projeto de vida e o próprio sentido da escolarização. Aqui se analisa especificamente a influência da educação católica sobre a constituição subjetiva dos estudantes, a partir da maneira como elaboram sua experiência educativa ao final da educação básica.

\section{A escola católica contemporânea e a crise das instituições}

Abordando temas relacionados à relação entre juventudes e escola, Dayrell (2007, p. 1106) aponta como primeiro passo na pesquisa evitar as análises lineares e "constatar que a relação da juventude com a escola não se explica em si mesma: o problema não se reduz nem apenas aos jovens, nem apenas à escola"; por isso o autor propõe "uma mudança do eixo da reflexão, passando das instituições educativas para os sujeitos jovens, onde é a escola que tem de ser repensada para responder aos desafios que a juventude nos coloca" (DAYRELL, 2007, p. 1107).

Na pesquisa em curso, este deslocamento da instituição católica para os sujeitos jovens possibilita descobrir os aspectos específicos da escolarização neste espaço-tempo, compreender os sentidos atribuídos pelos estudantes à educação básica e identificar a relação entre o processo de subjetivação e a educação católica. Como as percepções dos estudantes, seja validando a educação tal como se desenvolve ou apontando necessidades de mudança, são geradas a partir do cenário mais amplo, deve-se buscar compreendê-las a partir da rede de significados e tramas sociais constituídas na comunidade educativa. Isso porque

É preciso entender e refletir sobre a sociedade em que o jovem está inserido e na qual ele experimenta, circula e compartilha afetos. Também é preciso reconhecer que ele organiza essas trocas segundo uma coerência que persegue os sentidos estabelecidos nessa e por essa sociedade. (PEREIRA; LOPES, 2016, p. 195).

Quanto ao cenário educacional contemporâneo, destaca-se como fator preponderante a mudança fundamental no papel das instituições sociais: escola, família e religião deixam de ser instituições que "fabricam" indivíduos a partir da transformação de valores em normas e de normas em personalidades individuais (DUBET; MARTUCELLI, 2000). Dubet (2006 apud DAYRELL, 2007) identifica um processo de desinstitucionalização do social, resultante de um esgotamento do seu programa institucional e que pode ser entendido como a existência de um processo de mutação que transforma a própria natureza socializadora das instituições, fazendo com que uma parte importante do processo de subjetivação seja considerada tarefa ou ação do próprio sujeito sobre si mesmo. Segundo Pais (2003, p. 316), tal fato acontece "não porque as instituições estejam em declínio ou em vias de extinção, mas pelo fato de serem vias de mudança social”. Desta forma, os valores e normas que costumavam ser transmitidos pelas instituições

aparecem como coproduções sociais, conjuntos compostos por metas múltiplas e frequentemente contraditórias, coproduções nas quais os hábitos, os interesses diversos, instrumentais e emocionais, as políticas jurídicas e sociais desembocam em equilíbrios e formas mais ou menos estáveis no seio dos quais os indivíduos constroem suas experiências e se constroem como atores e como sujeitos. (DUBET; MARTUCELLI, 2000, p. 201).

Neste contexto, Kessler (2002) identifica como consequência um processo de desinstitucionalização e segmentação educacional, especialmente no ensino médio, porque, entre outras razões, 
a escolarização deixa de ser o garante de ingresso no mercado de trabalho e a obrigatoriedade do ensino médio, definida como política de Estado para universalizar o acesso de adolescentes e jovens à escolarização básica, se vê confrontada com a impossibilidade governamental de garantir educação de qualidade para todos os estudantes. Assim, se fragiliza o papel das instituições educativas e se engendra a separação de dois processos escolares que, na sociologia clássica, apareciam imbricados: a socialização, isto é, a inserção do estudante na sociedade, por meio da transmissão familiar e escolar dos conhecimentos, valores, normas e comportamentos socialmente validados; e a subjetivação, processo pelo qual o estudante se constitui sujeito na sociedade, a partir da apropriação destes mesmos referenciais sociais. Assim, vão perdendo homogeneidade as três funções básicas do ensino médio: "a formativa, ligada à socialização; a seletiva, com finalidade de orientar ao mercado de trabalho; e a relacional, que compreende a escola como um espaço de sociabilidade" (KESSLER, 2002, p. 24, tradução nossa). Confirma Dayrell (2007, p. 1124): "A escola perdeu o monopólio da socialização dos jovens, que vem ocorrendo em múltiplos espaços e tempos, principalmente naqueles intersticiais dominados pela sociabilidade".

Seguindo o deslocamento proposto pelo autor, é necessário "centrar a atenção no sujeito, pois sua existência ocupa nos enunciados posições que correspondem tanto ao sujeito de estado como ao sujeito do fazer durante o processo de formação" (PEDRAZA DÍAZ, 2015, p. 203, tradução nossa). Em outras palavras, são diferentes as percepções dos estudantes, ao final da escolarização básica, e dos educadores, gestores e famílias, que olham a escola a partir de outros lugares, etapas vitais e papéis nos processos educativos. É importante assinalar esta distinção, pois “é precisamente nestes estados e transformações neles percebidas que é possível reconhecer o que são para o jovem estudante a educação e a escola" (PEDRAZA DÍAZ, 2015, p. 203, tradução nossa). E aí se chega aos estudantes pesquisados, provocados a apresentar suas percepções sobre sua experiência educativa na escola católica.

\section{Estudantes e ensino médio: A escola serve para quê?}

Um dado curioso sobre os estudantes investigados é que muitos deles estudaram na mesma escola durante toda a vida, daí a opção metodológica de coletar dados nas séries finais do ensino médio e abordar questões sobre o cotidiano escolar, em vista de favorecer uma percepção mais ampla sobre as trajetórias escolares e os aspectos específicos da educação católica. Apesar desses critérios de seleção, não se esperavam percepções homogêneas sobre a escolarização, pois, como sinaliza Rockwell (2018, p. 24, tradução nossa), nos adolescentes e jovens as "experiências subjetivas do tempo transcorrido são distintas e contribuem para a heterogeneidade inerente a qualquer grupo escolar".

Esta heterogeneidade, perceptível no interior de cada escola, ganhou mais amplitude no conjunto de escolas investigadas. Por essa razão, as respostas foram analisadas a partir da Epistemologia Qualitativa e seu conceito de sentidos subjetivos, definidos como "unidades simbólico-emocionais, nas quais o simbólico se torna emocional desde sua própria gênese, assim como as emoções vêm a ser simbólicas, em um processo que define uma qualidade dessa integração, que é precisamente a definição ontológica da subjetividade" (GONZÁLEZ REY; MARTÍNEZ, 2017, p. 63). Para os autores, os sentidos subjetivos são "a unidade mais elementar, dinâmica e versátil da subjetividade", destacando que "sua emergência não é uma soma, mas um novo tipo de processo humano [...] que emerge na vida social culturalmente organizada, permitindo a integração do passado e do futuro como qualidade inseparável da produção subjetiva atual" (GONZÁLEZ REY; MARTÍNEZ, 2017, p. 63).

Deste conceito se destaca a relação entre sentido subjetivo, memória do vivido e prospectivas de futuro, centrais na etapa de vida dos estudantes secundaristas. Weiss (2012) lembra 
que os secundaristas, além de estudantes, são também adolescentes e jovens vivendo uma etapa de seu desenvolvimento vital que ocorre concomitante ao ensino médio; por essa razão, não é possível estabelecer uma separação entre suas percepções sobre a escolarização e as questões próprias desta fase da adolescência. Assim,

Falar de educação formal e escola na perspectiva do educando é partir do conhecimento experiencial, é indagar os imaginários impregnados de vivências, as formas de vida particulares nas quais se enuncia como os educandos se percebem no processo educativo e na vida cotidiana escolar. (PEDRAZA DÍAZ, 2015, p. 203, tradução nossa).

Mendonça (2011, p. 351), analisando o ensino médio hoje, constata que os estudantes "reconhecem na escola o seu papel de transmissora de conhecimentos, ou seja, o seu significado social, ao afirmarem que o papel da escola é ensinar". A autora complementa que, mesmo existindo "um reconhecimento e legitimidade da escola quanto a sua especificidade", o interesse discente pela escola "passa mais pelo espaço de sociabilidade que esta possibilita, do que pelo acesso a conteúdos escolares", ou seja, "os estudantes gostam da escola, mas não da sala de aula. Apreendem o significado social da instituição, porém não o veem presente diretamente em suas vidas, não lhe atribuem sentido" (MENDONÇA, 2011, p. 351).

Kessler (2002) reconhece esta dissociação em circuitos educativos nos quais não se alcança a qualidade educacional esperada, devido a fatores sociais, pedagógicos e governamentais que fragilizam a experiência escolar - o que não é o caso dos estudantes envolvidos nesta pesquisa. $\mathrm{Na}$ última pergunta do questionário, eles foram provocados a responder com \#hashtags, de maneira livre e com quantas palavras quisessem, à questão: A escola serve para quê? As respostas foram organizadas em dois gráficos: o primeiro considerou a primeira hashtag escrita por cada estudante, que representa sua associação mais imediata com o sentido da escola; e o segundo agrupou as palavras e expressões mais mencionadas do total de respostas, o que sugere uma visão mais elaborada sobre a questão. Como as respostas foram espontâneas, há muitas palavras distintas, e a categorização facilita compreender em conjunto estas percepções.

\section{Gráfico 1 - Primeiras palavras mencionadas pelos estudantes para expressar a finalidade da escola}

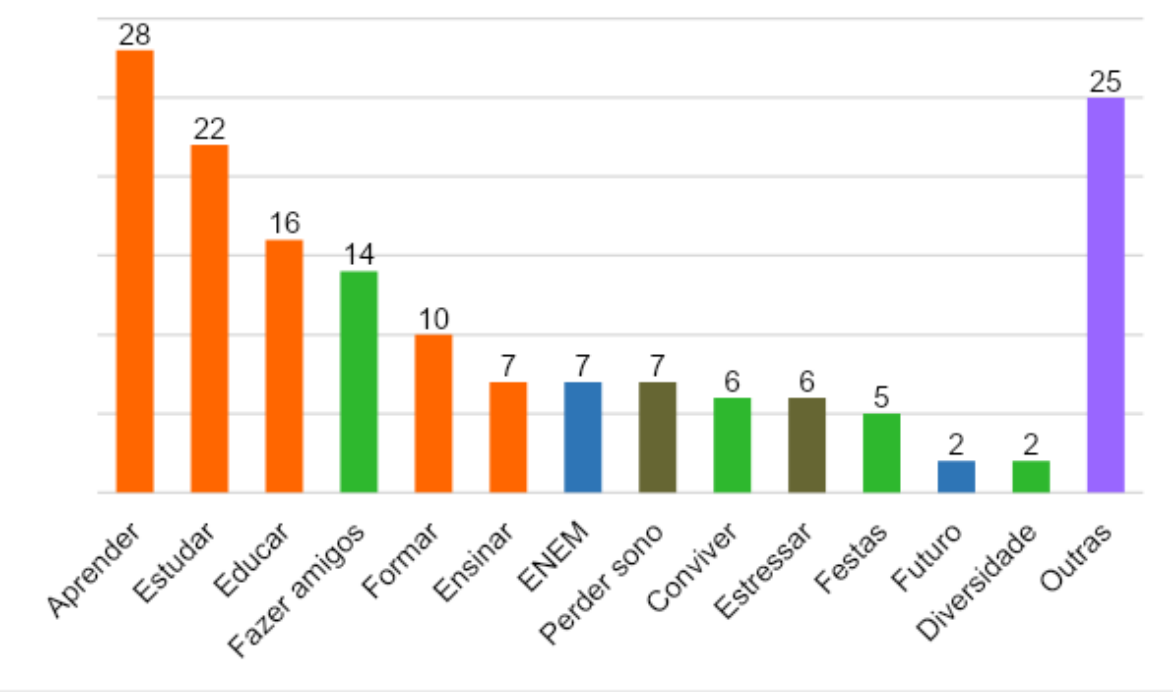

Fonte: Elaborado pelo autor. 


\section{Gráfico 2 - Palavras mais mencionadas pelos estudantes para expressar a finalidade da escola}

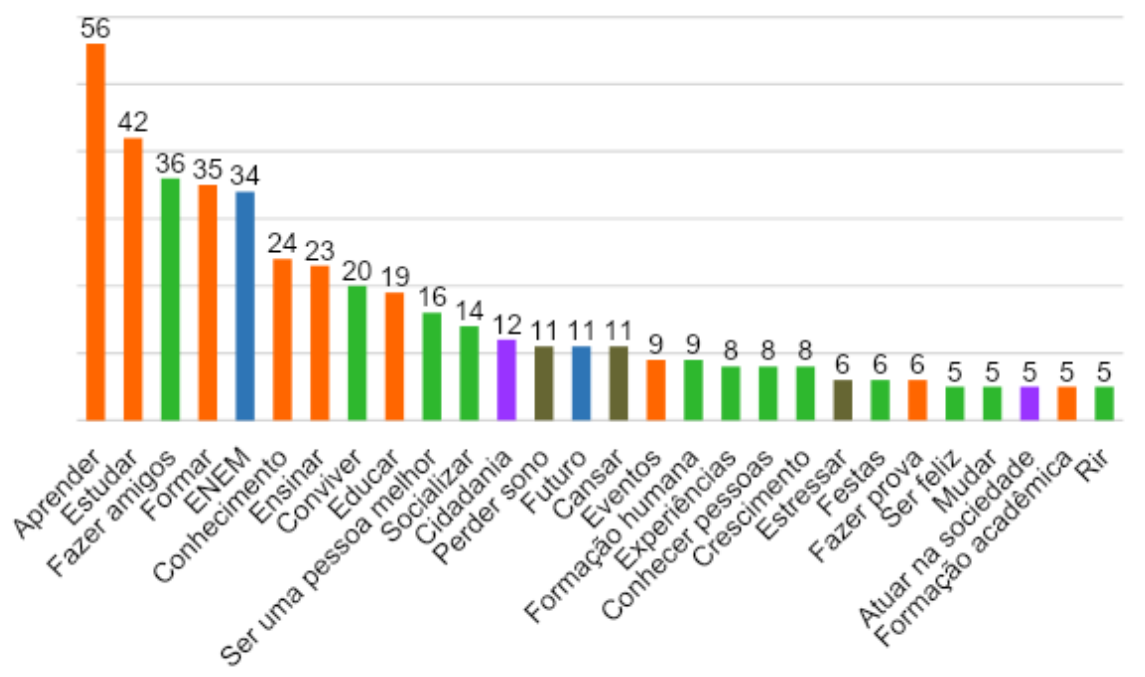

Fonte: Elaborado pelo autor.

Legenda:

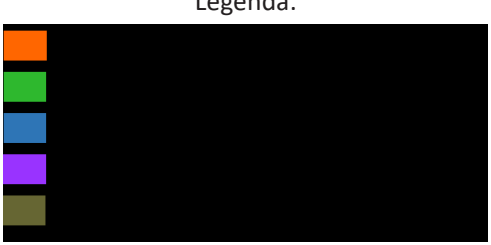

Chama atenção que os dois gráficos tragam as mesmas primeiras palavras - e ambas relacionadas ao ofício do estudante: "aprender" e "estudar"; as funções da escola - "educar", "formar", "ensinar", "conhecimento" - aparecem depois, complementadas por "eventos" (9), "fazer prova" (6) e "formação acadêmica" (5). O ENEM se encontra entre as palavras mais mencionadas, mas não entre as primeiras, sinalizando que os estudantes, apesar da preocupação com o ingresso na universidade, associam outros elementos importantes à experiência escolar. Os aspectos relacionados à sociabilidade se expressam em mais palavras, o que não surpreende: por serem adolescentes, atribuem muita importância a "fazer amigos" (36), "conviver" (20), "ser uma pessoa melhor" (16), "socializar" (14), "formação humana" (9), "experiências", "conhecer pessoas", "crescimento" (8), "festas" (6), "ser feliz", "mudar", "rir" (5). A formação cidadã aparece em duas palavras - "cidadania" (12) e "atuar na sociedade" (5) - e aspectos socioemocionais, em três: "perder sono", "estressar" (11) e "cansar" (6). As "Outras" palavras do primeiro gráfico são "divertir-se" (3), "diversidade" (3), "formação social", "formação da identidade", "ser mais empático", "complementar a educação", "base acadêmica", "1000 no ENEM", "visão de mundo", "esclarecer", "preparação", "amar", "sofrer", "passar frio", "acordar cedo", "a vida não é fácil", "encher o saco", "matar psicologicamente", "passar raiva", "tudo" e "nada" (1). Muitas percepções se repetem, enquanto outros estudantes trazem associações mais livres e fora do padrão - nesta questão e em outras.

Vista em conjunto, as respostas sugerem que a maioria dos estudantes, mesmo apontando a necessidade de mudanças na educação, expressa uma visão positiva sobre a escola e destaca, em ordem de importância, as funções básicas de ensino e aprendizagem, sociabilidade e preparação para a continuidade dos estudos, conforme definido pela Lei de Diretrizes e Bases da Educação Básica (1996). Os estudantes destacam a sociabilidade como um elemento importante da escolarização e estabelecem vínculos afetivos com o espaço-tempo escolar, no qual vivenciam experiências de encontro, amizades, autoconhecimento, relações, convivência e experimentações características da própria adolescência. Entretanto, reconhecem também o papel da escola na transmissão e produção do conhecimento, 
socialização, preparação para o prosseguimento dos estudos e definição do projeto de vida. Assim se confirma a observação de Kessler (2002): ainda que as escolas em geral venham perdendo homogeneidade em suas funções formativa, seletiva e relacional, esta perda acontece em menor escala em alguns grupos de escolas privadas. Segundo o autor, a visão positiva destes estudantes tem relação direta com sua percepção da escola como espaço-tempo de subjetivação, pois nelas

se gera uma narrativa escolar de alta eficácia simbólica, não necessariamente porque cumpre os objetivos que promete, mas porque é um discurso institucional que mantém sua potência como produtor de subjetividade, isto é, capaz de constituir um sujeito em torno de um conjunto de normas e valores que regem seu lugar na vida social. (KESSLER, 2002, p. 38-39, tradução nossa).

Levando em conta o tempo que passam na escola, não surpreende que os estudantes reconheçam a importância deste espaço-tempo no seu processo de subjetivação - ainda que não utilizem esta expressão, explicitam seu significado em várias falas. Daí a necessidade de, além de deslocar o foco da instituição educativa para os sujeitos, como aponta Dayrell (2007), ampliar a abordagem teórica, cruzando distintos campos do conhecimento nos estudos desenvolvidos com e sobre os jovens. Afirma Weiss (2012, p. 138, tradução nossa): nas pesquisas focadas no ensino médio, "a teorização sobre os jovens requer ir além dos conceitos de sociabilidade e socialização; necessita recuperar o conceito de subjetivação, ou seja, a noção de que, paralelamente ao processo de socialização, se desenvolve o processo de subjetivação". Esta questão suscita outras possibilidades interessantes, abordadas em seguida.

\section{Escola católica e processos de subjetivação juvenil}

Questões relacionadas a identidade, subjetividade e subjetivação ganham relevância no contexto contemporâneo devido à diversidade de configurações subjetivas e variáveis identitárias até então inéditas e/ou pouco reconhecidas. Os marcadores de classe, cultura, pertença religiosa, etnia, gênero e geração, entre outros, influenciam na constituição dos sujeitos e suas trajetórias de vida. Para Pavloski (2012, p. 13), esta é uma consequência do "turbilhão de rupturas e transformações que definiram a modernidade", cuja "dissolução da suposta integridade que caracterizou o conceito tradicional de identidade é, de forma insuspeita, um dos signos indeléveis do período"; desta forma, "tanto na esfera pública quanto privada, as transfigurações dos paradigmas identitários substituíram a unicidade pela multiplicidade e a solidez pela desconstrução". Bauman (2005, p. 35) confirma: no mundo contemporâneo, "as identidades ganharam livre curso, e agora cabe a cada indivíduo, homem ou mulher, capturá-las em pleno voo, usando os seus próprios recursos e ferramentas". Dubet (2007), por sua vez, relaciona esta fluidez à mencionada desinstitucionalização do social e à consequente fragilização das instituições que tradicionalmente validaram as formas de organizar a subjetividade.

De qualquer forma, "o percurso subjetivo é marcado por circuitos institucionais" e, ainda que estes tenham perdido parte de sua exclusividade como agências de subjetivação, "a família e a escola são as instituições nas quais se produzem as primeiras experiências vitais e constituem o ponto de partida dos itinerários posteriores, com seus trajetos, pontos, cortes, articulações e fraturas" (RASCOVAN, 2016, p. 241-242, tradução nossa). Nessa perspectiva, Sibilia (2008) aponta as questões imbricadas no próprio conceito de subjetividade: "Como e por que alguém se torna o que é, aqui e agora? O que nos constitui como sujeitos históricos, indivíduos singulares, embora também inevitáveis representantes de nossa época, partilhando um universo e certas características idiossincráticas com nossos contemporâneos?" Como tentativa de resposta, a autora relaciona a constituição subjetiva não tanto aos circuitos institucionais, mas ao contexto cultural: 
Se as subjetividades são modos de ser e estar no mundo, longe de toda essência fixa e estável que remete ao "ser humano" como uma entidade a-histórica de relevos metafísicos, seus contornos são elásticos e mudam ao sabor das diversas tradições culturais. Assim como toda subjetividade é necessariamente embodied, encarnada em um corpo, ela também é sempre embedded, embebida em uma cultura intersubjetiva. [...] E é inegável que nossa experiência também seja modulada pela interação com os outros e com o mundo. Por isso, é fundamental a pregnância da cultura na conformação do que se é. (SIBILIA, 2008, p. 15-16).

Mesmo situando a educação católica na perspectiva da tradição cultural e reconhecendo sua influência na formação dos estudantes, a escola não se constitui o único espaço-tempo a partir do qual eles se tornam sujeitos. Como apontam Grassi e Córdova (2010, p. 20, tradução nossa), "o processo de subjetivação é a ação de dar sentido, de significar e pôr uma marca de origem, (assinar) um processo de metabolização. Dar um sentido pessoal, um made in my name acompanhado do ato que isso sempre implica", pois "a subjetividade é matéria que se produz no intercâmbio entre outros sistemas (intrapsíquico), pelo intercâmbio com os outros (intersubjetivo), pelo intercâmbio com o meio (transubjetivo)". Portanto, a produção subjetiva "está en-red(ada) com o corpo, com a história, com o meio, com a cultura, com a genealogia" (GRASSI; CÓRDOVA, 2010, p. 20, tradução nossa). Na mesma direção, Weiss (2012) assinala que

As identidades se constroem em um duplo processo de socialização (interiorização de normas e valores) e de subjetivação (emancipação e elaboração de normas e valores próprios), sobretudo na convivência com os outros (sociabilidade). O processo de socialização e de subjetivação é um processo nunca acabado, mas são os jovens que o vivem com maior intensidade. Eles exploram continuamente diferentes âmbitos e maneiras de interagir. As identificações são geradas na prática social e vividas na e por meio da ação em diferentes âmbitos da vida ou mundos figurados. (WEISS, 2012, p. 141, tradução nossa).

Segundo o autor, os mundos figurados são âmbitos de interação nos quais os atores realizam certo tipo de atividades que requerem o desenvolvimento de determinados conhecimentos e habilidades; compartilham certos significados, normas e valores em suas interações; e ocupam determinadas posições e hierarquias. Em se tratando de adolescentes, a escola constitui-se como um mundo figurado com papel estratégico nos processos de subjetivação, como apontam Sposito e Galvão (2004, p. 364): "Entre a ação de ensinar e o aprender, situa-se o sujeito que reivindica estar implicado e que demanda realizar um trabalho pessoal tendo em vista o seu processo de construção como aluno do ensino médio". Nessa tarefa se imbricam a socialização e a sociabilidade, pois, como observa Abrantes (2003, p. 122), as identidades juvenis e as dinâmicas de escolarização não são criadas em esferas independentes, mas resultam dos mesmos processos e "desenvolvem-se em constante articulação, sedimentando-se e reconfigurando-se"; por essa razão, "o percurso de escolaridade é, ele próprio, uma sucessão de interações sociais nas quais se vão construindo e sedimentando identidades". Finaliza o autor: a escola "está cada vez mais presente nos cotidianos juvenis. Todavia, os jovens não vão simplesmente à escola: apropriam-se dela, atribuem-lhe sentidos e são transformados por ela" (ABRANTES, 2003, p. 122).

E o que dizem os adolescentes acerca destas questões? Perguntados se a escola, além de proporcionar o conhecimento acadêmico, lhes ajuda a lidar com as questões pessoais, relacionais e sociais - cujas interseções contribuem para a constituição subjetiva -, os estudantes apresentaram as respostas agrupadas no gráfico seguinte: 


\section{Gráfico 3 - Contribuições da escola para a formação dos estudantes, além do conhecimento acadêmico}

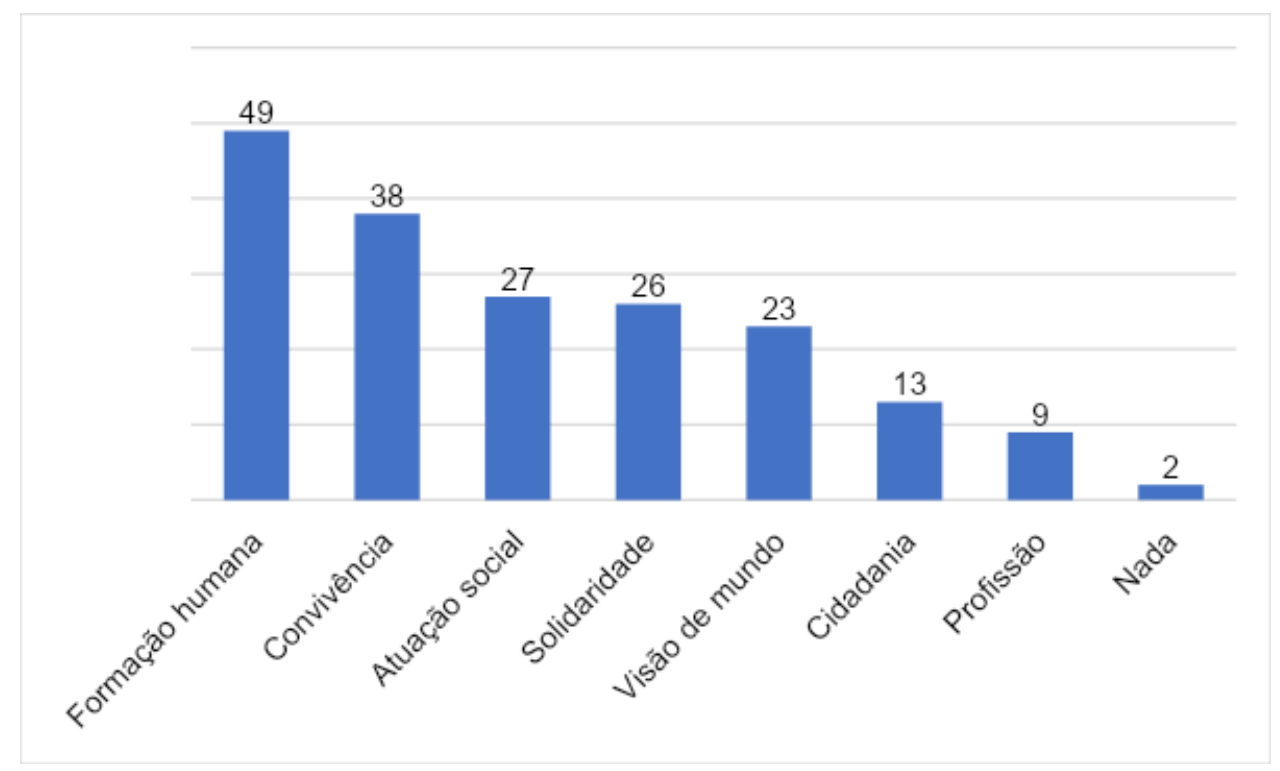

Fonte: Elaborado pelo autor.

Vistas em conjunto, as respostas explicitam os aspectos envolvidos no processo de subjetivação: as dimensões individual, grupal e social; as tarefas consideradas inerentes à escolarização, como a formação humana, cidadã e profissional; e a interação com outros sujeitos. Nas palavras dos estudantes, são estas as contribuições da escola para seu processo de tornar-se sujeitos:

Estudo no colégio há 12 anos, e isso claramente definiu a pessoa que eu sou hoje. Meus valores, pensamentos e inteligência foram feitos aqui. (C5E22) 2 .

Estudo há muitos anos no colégio e ele foi responsável pela formação de muitas características minhas. (...) Aqui aprendi a me relacionar melhor com as pessoas e lidar com responsabilidades. (C6E12).

Aprendi muitas coisas na escola que levo para a vida toda, como um melhor diálogo com as pessoas e acho isso importante, pois escola não é só aprendizagem acadêmica, mas também aprendizagem para a vida. (C3E14).

O autoconhecimento, reconhecer o espaço onde vivo e o que faço para mudá-lo como cidadão, o papel religioso, onde eu me enxergo no mundo e como enxergo o outro. (C1E16).

A escola me ajudou muito a aumentar a minha autonomia e a me preparar para a vida. Tornei-me alguém muito mais responsável e de cabeça aberta para o mundo. (C5E25).

A percepção destes estudantes confirma a relação entre o processo de escolarização e a subjetivação, destacada anteriormente. Apesar disso, é necessário reconhecer que

A identidade juvenil se manifesta como uma construção inacabada. Os sujeitos infanto-juvenis, ao traçar seus sulcos biográficos, vão provando opções de adscrição identitária, desenvolvem processos de identificação com o que encontram no mundo por meio de núcleos de pertencimento (ideias, modelos, concepções) e de referência (lugares, territórios). (CACHORRO, 2016, p. 3, tradução nossa).

Nessa perspectiva, o processo de subjetivação resulta na definição da identidade, mas esta permanece em construção e nunca será apenas pessoal. Como indica Weiss (2012, p. 141), reforçando 
a indissociabilidade entre ensino médio e subjetivação juvenil, perguntas como "Que faço e quem sou? Que vou fazer da vida e quem quero ser?" confirmam como "a construção de uma identidade é um assunto importante para os jovens, tanto a construção de uma identidade social ou cultural quanto de uma identidade pessoal"; afinal, "os jovens estão em um processo contínuo de identificar-se com outros (pares) e distinguir-se de outros (pares)". Nesse sentido, a interação com outras realidades sociais e sujeitos, para além da própria escola e dos circuitos institucionais, ganha importância, especialmente considerando-se o perfil socioeconômico dos estudantes que frequentam a escola católica.

\section{Estudantes secundaristas, sociabilidade e cidadania}

Ainda que a distinção entre socialização e sociabilidade seja mais teórica que prática, ambos os processos envolvem as dimensões pessoal, coletiva e social e apresentam referenciais para o processo de subjetivação. Muitos estudantes relatam participar de projetos escolares extraclasse, geralmente de cunho solidário e pastoral, justificando seu interesse pela interação com outros sujeitos, conhecimento de realidades distintas e aprendizagens construídas fora do espaço-tempo escolar. Assim, a escola católica favorece a convivência cotidiana entre os pares, certamente, mas também proporciona aos estudantes interações com realidades com as quais dificilmente teriam contato, pelo estrato social ao qual pertencem. Tais experiências, mesmo fazendo parte da formação integral proposta pela educação católica, ganham mais relevância no ensino médio, quando os adolescentes tendem a buscar experimentações e interagir em espaços diversos. Portanto,

É preciso não perder de vista que a escola é um espaço de interação e de convivência entre diferentes, mas não o único espaço, e nem atuando isoladamente. Sem dúvida, a instituição escolar sempre esteve integrada a um contexto mais amplo e pode ser um dos muitos lugares onde se tecem redes de sociabilidade e muitos modos e estratégias de participação social. (PEREIRA-TOSTA, 2011, p. 428).

Vários estudantes confirmam a escola como potencializadora de experiências para além do espaço-tempo escolar e, além de reconhecerem tais iniciativas como um diferencial da educação católica, consideram-nas geradoras de aprendizagens muitas vezes mais significativas que o conteúdo trabalhado em sala de aula:

Graças a algumas iniciativas já citadas nas atividades que são fora da sala de aula, sinto que o colégio X me ajuda MUITO. (C1E1).

O colégio $\mathrm{X}$ foi a raiz de toda a minha formação pessoal. Acredito ter um olhar diferente sobre o outro, podendo ser mais compreensiva e menos individualista. As experiências adquiridas na minha vida escolar foram fundamentais para eu acreditar que posso fazer a diferença. (C4E11).

Como o colégio X é envolvido com vários projetos sociais, eu acho que ele nos ajuda a mudar o mundo com base na realidade do outro, contribuindo para melhorar a qualidade de vida daquelas pessoas. (C2E24).

Vale assinalar que os projetos solidários das escolas tendem hoje a abandonar o caráter assistencialista e pontual de outrora e evoluir para iniciativas mais estruturadas, que implicam a instituição educativa e dos estudantes em realidades socialmente vulneráveis. As escolas envolvidas na pesquisa possibilitam aos estudantes experiências de voluntariado em parceria com outras instituições, mantendo uma participação regular ao longo do ano. Essa opção favorece aos estudantes a interação com outras pessoas e entidades que atuam em causas sociais diversas, 
conforme os interesses dos próprios estudantes, razão pela qual estes estabelecem relação direta entre a participação em tais experiências e sua formação como sujeitos:

A questão da solidariedade. Desde que eu comecei a estudar aqui, me ensinam a importância de cuidar e ajudar o outro. É algo que fez grande diferença para mim e faz parte da minha personalidade." (C5E5).

O colégio possui projetos humanizadores que me possibilitaram ser uma pessoa mais sensível e aberta. A Missão de Solidariedade foi um desses principais mobilizadores e com ela conheci pessoas que, hoje, cada vez mais, abrem minha consciência para a diversidade. (C2E30).

Creio que de certa forma o colégio me tornou mais sustentável em relação a algumas questões ambientais e em ser mais respeitosa e gentil com aqueles que convivo. (C6E22).

A bagagem adquirida contribui para que eu possa criar alternativas para ajudar necessitados, em todos os sentidos, que é um desejo meu no futuro, além de auxílio para pessoas com baixa escolaridade em regiões menos abastadas, de todas as idades (auxílio tanto psicológico quanto estudantil). (C2E31).

Acho um diferencial no colégio ter muitas bolsas [sociais], faz com que o colégio seja menos elitista. Além de ser um colégio que permite a individualidade dos alunos, a convivência com a diferença me faz ser uma pessoa melhor, com uma cabeça mais aberta. (C5E12).

Os valores da alteridade, ética, respeito, excelência e serviço são parte do nosso ser e caráter, graças ao longo processo que passamos aqui. Dentre todos, seremos destaque, e destaque para o bem comum! (C1E8).

É curioso que muitos estudantes participam de projetos sociais, especialmente o voluntariado, e ressaltam as aprendizagens geradas nessas interações, mas demonstram resistência às atividades pastorais. Se a escola tem identidade católica, seria de se esperar adesão dos estudantes a iniciativas de evangelização explícita; entretanto, estes ecoam a mesma rejeição à religião institucionalizada manifestada por outros grupos juvenis. Diz um deles:

A escola proporciona um lado mais humano do ensino, não relacionado a questões acadêmicas, através da formação cristã. Em minha opinião, tais atividades são muito ligadas à religião e poderiam despertar mais interesse nos alunos se não fossem. Mas não posso reclamar, afinal, estou em uma escola católica. (C1E3).

Não é intenção aprofundar as questões religiosas neste artigo; esta pontuação ilustra a diversidade de experiências de escolarização vivenciadas pelos estudantes, mesmo circulando por circuitos institucionais semelhantes, e confirma a mencionada crise das instituições tradicionais: os estudantes optam pela educação católica, mas resistem a participar de projetos explicitamente pastorais.

De qualquer forma, estas experiências vinculadas à escola, mas desenvolvidas em outros espaços, dão mais concretude à compreensão de cidadania ao favorecer a interação com realidades de desigualdade e exclusão social. Nessa direção, Pais e Feixa (2020, p. 246-247) problematizam "o conceito tradicional de cidadania, limitado aos direitos e obrigações sociais", e identificam entre os jovens socialmente vulneráveis uma "cidadania participativa, de expressão artística e criativa, a partir de diversas manifestações da cultura juvenil”. Esta concepção soa atrativa para os estudantes, e pode-se reconhecê-la em várias falas: indagados sobre quais contribuições podem aportar à sociedade, a partir da educação católica, alguns expressam o desejo de "mudar o mundo"; se o termo em si soa algo ingênuo, ganha outro sentido na boca dos adolescentes, que tendem a expressar com intensidade suas ideias e causas. Revelando algum nível de inconformismo com a ordem social, manifestam a tendência geracional de pensar globalmente e agir localmente, relacionando a ação individual ao contexto mais amplo: 
Apesar de muitas pessoas falarem que uma pessoa não muda o mundo sozinha, aprendi que os valores aprendidos devem ser compartilhados, pois, quanto mais pessoas alcançamos com ideias que poderão mudar o mundo, juntas, essas ideias se realizarão. (C2E28).

O colégio proporciona variedades de conhecimento e realidades que geram uma ampla e clara visão de mundo, o que contribui para mudá-lo. (C5E6).

Aqui vivi experiências que me fizeram enxergar o outro e ver os problemas por que a sociedade passa, e graças a isso hoje eu sou uma pessoa que procura achar soluções para melhorar os problemas que ela sofre. (C1E2).

A mobilização das pessoas para ajudar projetos sociais, fazer diferença com a educação das próximas gerações. (C2E8).

Outros estudantes envolvidos em projetos solidários compreendem que a atuação em projetos sociais demanda mudanças na estrutura da sociedade e reconhecem nessa participação um exercício de cidadania que deve ser ampliado para a vida em sociedade:

O colégio me ofereceu uma visão mais ampla de outras realidades, o que eu considero de extrema importância para escolher novos representantes políticos, além de ter me dado mais vontade de realizar trabalhos voluntários e de ativismo social, que não necessariamente estejam integrados ao colégio. (C2E35).

O colégio nos dá uma educação que preza pelo conhecimento, senso crítico e observador, logo, a diferença que nós podemos fazer é dizer não a opressões, pessoas doidas no poder, etc. (C5E26).

Por ter estudado no colégio, eu percebo o quanto o mundo é desigual e o quanto somos privilegiados. A partir disso, eu pretendo possibilitar algumas coisas para as pessoas que não têm condições. (C2E14).

Tais falas ecoam uma tarefa da educação contemporânea, segundo a Base Nacional Curricular Comum (BNCC): "É, também, no ambiente escolar que os jovens podem experimentar, de forma mediada e intencional, as interações com o outro, com o mundo, e vislumbrar, na valorização da diversidade, oportunidades de crescimento para seu presente e futuro" (BRASIL, 2018, p. 473). Considerando-se as finalidades do ensino médio, referendadas pela BNCC, pode-se encontrar nessa assertiva tanto os fundamentos do projeto educativo quanto indicativos para que as mediações pedagógicas proporcionem uma experiência de educação integral e contribuam na constituição de sujeitos abertos, solidários, comprometidos com o bem comum e atuantes na sociedade. No que tange à escola católica, estas características são explicitadas na visão antropológica que fundamenta o projeto educativo, mas não alcança todos os estudantes, conforme se viu, já que a diversidade também marca as experiências de escolarização. Um estudante confirma esta diversidade, ao referir-se aos sujeitos constituídos a partir da educação católica:

Ressalto a importância de uma formação pessoal. Claro que os alunos interpretaram e resolveram absorver ou não esses ensinamentos de um jeito pessoal, mas vejo em geral um grande aproveitamento. (C1E6).

\section{Considerações finais}

A constituição do sujeito jovem resulta de um processo idiossincrático influenciado por fatores familiares, culturais, religiosos e educacionais relacionados a um contexto social determinado. Estes elementos caracterizam a diversidade juvenil e, portanto, devem ser considerados na pesquisa com e sobre os sujeitos jovens. Além disso, se a pesquisa tem foco na escolarização, 
é importante não esquecer que o estudante, além de constituir um segmento da população, é também um adolescente/jovem em processo de constituição subjetiva; logo, as questões próprias dessa etapa de desenvolvimento merecem tanta atenção quanto a caracterização social, a realidade do entorno escolar e a cultura juvenil como aí se manifesta.

Quanto aos estudantes envolvidos na pesquisa, percebem-se elementos comuns aos processos de subjetivação vividos por outras juventudes, devido às características da etapa de desenvolvimento, e peculiaridades conferidas pelo contexto familiar, social, educacional, religioso... Os estudantes confirmam a perda de exclusividade das instituições sociais na constituição dos sujeitos, especialmente a instituição religiosa, mas expressam uma visão positiva sobre os espaços institucionais, talvez porque encontram neles a segurança e suporte social que faltam a jovens na mesma etapa vital e de escolarização, mas vivendo-as em realidades socialmente vulneráveis. Pela mesma razão, e sem deixar de reconhecer as tarefas individuais envolvidas no processo de tornar-se sujeito, os estudantes envolvidos na pesquisa percebem uma relação positiva entre sua constituição subjetiva e as interações intersubjetivas proporcionadas a partir do espaço-tempo da escola católica.

Outro aspecto significativo é a diversidade de percepções sobre a experiência escolar. Se outros estudos identificam uma percepção negativa de adolescentes e jovens pobres sobre a educação - que, nas periferias em geral, tende a ser precarizada e de baixa qualidade -, os estudantes investigados apresentam uma percepção predominantemente positiva sobre a escola, interpretando como enriquecedoras as experiências educativas proporcionadas pela escola católica. Ainda que tenham como referência a instituição educativa confessional, vivenciam experiências variadas neste espaço-tempo escolar e, assim, se constituem como sujeitos plurais e diversos, inclusive no aspecto religioso e social.

Por fim, a pesquisa se encontra em andamento. Confrontar as percepções dos estudantes com as dos gestores, educadores e pastoralistas certamente apontará outros elementos significativos aos processos de constituição subjetiva destes adolescentes e jovens, trazendo outras contribuições aos estudos sobre as juventudes.

\section{Referências}

ABRANTES, Pedro. Os sentidos da escola: identidades juvenis e dinâmicas de escolaridade. Oeiras: Celta Editora, 2003.

BAUMAN, Zygmunt. Identidade: entrevista a Benedetto Vecchi. Tradução Carlos Alberto Medeiros. 1. ed. Rio de Janeiro: Jorge Zahar, 2005.

BRASIL. Ministério da Educação. Base Nacional Comum Curricular. Brasília, DF: Fundação Carlos Alberto Vanzolini, 2018.

CACHORRO, Gabriel. Jóvenes: identidades, cuerpo y subjetividad. Procesos de subjetivación y dessubjetivación. Actas de Periodismo y Comunicación, Buenos Aires, v. 2, n. 1, dic. 2016.

DAYRELL, Juarez. A escola "faz" as juventudes? Reflexões em torno da socialização juvenil. Educação \& Sociedade, Campinas, v. 28, n. 100, p. 1105-1128, out. 2007.

DUBET, François. El declive y las mutaciones de la institución. Revista de Antropología Social, Madrid, v. 16, p. 39-66, 2007.

DUBET, François; MARTUCCELLI, Danilo. En la escuela: sociología de la experiencia escolar. Buenos Aires: Losada, 2000.

GONZÁLEZ REY, Fernando. Pesquisa qualitativa e subjetividade: os processos de construção da informação. São Paulo: Pioneira Thomson Learning, 2005.

GONZÁLEZ REY, Fernando; MARTÍNEZ, Albertina Mitjáns. Subjetividade: teoria, epistemologia e método. Campinas: Editora Alínea, 2017. 
GRASSI, Adrián; CÓRDOVA, Néstor. Entre niños, adolescentes y funciones parentales. Buenos Aires: Entreideas, 2010. INSTITUTO CIDADANIA. Projeto Juventude. São Paulo: Instituto Cidadania, 2004.

KESSLER, Gabriel. La experiencia escolar fragmentada. Estudiantes y docentes en la escuela media en Buenos Aires. Buenos Aires: Unicef, 2002.

MENDONÇA, Sueli Guadelupe de Lima. A crise de sentidos e significados na escola: a contribuição do olhar sociológico. Cadernos Cedes, Campinas, v. 31, n. 85, p. 341-357, set./dez. 2011.

PAIS, José Machado. Ganchos, tachos e biscates: jovens, trabalho e futuro. Lisboa: Âmbar, 2003.

PAIS, José Machado; FEIXA, Carles. Persiguiendo los vientos del tiempo: jóvenes, pasados compuestos y futuros posibles. Ultima Década, Santiago, v. 28, n. 53, p. 235-252, ago. 2020.

PAVLOSKI, Evanir. Identidades instáveis: os fragmentos do sujeito moderno. In: SALEH, Pascoalina Bailon de Oliveira; HARMUCH, Rosana Apolonia (org.). Identidade e subjetividade: configurações contemporâneas. Campinas: Mercado de Letras, 2012. p. 13-31.

Disponível em: https://www.academia.edu/22813147/Identidades_inst\%C3\%A1veis_os_fragmentos_do_sujeito_moderno. Acesso em: 29 jan. 2021.

PEDRAZA DÍAZ, Diana Marcela. Discurso pedagógico en maestros desde lo enunciado por estudiantes de colegios católicos. Cuadernos de Lingüística Hispánica, Colombia, n. 26, p. 199-214, jul./dic. 2015.

PEREIRA, Beatriz Prado; LOPES, Roseli Esquerdo. Por que ir à escola? Os sentidos atribuídos pelos jovens do ensino médio. Educação \& Realidade, Porto Alegre, v. 41, n. 1, p. 193-216, jan./mar. 2016.

PEREIRA-TOSTA, Sandra. Antropologia e educação: culturas e identidades na escola. Magis: Revista Internacional de Investigación en Educación, Bogotá, v. 3, n. 6, p. 413-431, enero./jun. 2011.

RASCOVAN, Sergio Eduardo. Los caminos de la vida. In: KORINFELD, Daniel; LEVY, Daniel; RASCOVAN, Sergio Eduardo. Adolescentes y adultos en la escuela. Puntuaciones de época. Buenos Aires: Paidós, 2016. p. 241-267.

ROCKWELL, Elsie. Temporalidad y cotidianeidad en las culturas escolares. Cuadernos de Antropología Social, Buenos Aires, n. 47, p. 21-32, 2018.

SIBILIA, Paula. O show do eu: A intimidade como espetáculo. Rio de Janeiro: Nova Fronteira, 2008.

SPOSITO, Marilia Pontes; GALVÃO, Izabel. A experiência e as percepções de jovens na vida escolar na encruzilhada das aprendizagens: o conhecimento, a indisciplina, a violência. Perspectiva, Florianópolis, v. 22, n. 2, p. 345-380, jul./dez. 2004.

WEISS, Eduardo. Los estudiantes como jóvenes. El proceso de subjetivación. Perfiles Educativos, México, v. 34, n. 135, p. 134-148, 2012.

Data de submissão: 31/01/2021

Data de aceite: 13/02/2021 